\title{
Chapter 8 \\ Tibetan Macaque Social Style: Covariant and Quasi-independent Evolution
}

\author{
Krishna N. Balasubramaniam, Hideshi Ogawa, Jin-Hua Li, Consuel Ionica, \\ and Carol M. Berman
}

\subsection{Introduction: Primate Sociality and Social Structure}

In animals, including primates, group living and the social tendencies that support it evolve when the benefits of living in groups (e.g., predator avoidance, cooperative resource sharing) outweigh the costs (e.g., competition for resources, disease risk) (Kappeler and Van Schaik 2002). Primate species share close evolutionary histories and are biologically, socially, and physiologically similar to humans (Cobb 1976; Kappeler et al. 2015; Suomi 2011). As such, they make excellent comparative models for understanding the evolution of aspects of human group living, an endeavor that is fundamentally important given that social connectedness is

\footnotetext{
K. N. Balasubramaniam $(\bowtie)$

Department of Population Health and Reproduction, School of Veterinary Medicine, University of California at Davis, Davis, CA, USA

H. Ogawa

School of International Liberal Studies, Chukyo University, Toyota, Aichi, Japan

e-mail: hogawa@lets.chukyo-u.ac.jp

J.-H. Li

School of Resources and Environmental Engineering, Anhui University, Hefei, Anhui, China International Collaborative Research Center for Huangshan Biodiversity and Tibetan Macaque Behavioral Ecology, Anhui, China

School of Life Sciences, Hefei Normal University, Hefei, Anhui, China

e-mail: jhli@ahu.edu.cn

C. Ionica

Biomedical Department, F. I. Rainer Anthropology Institute, Romanian Academy, Bucureşti, Romania

C. M. Berman

Department of Anthropology and Graduate Program in Evolution Ecology and Behavior, State University of New York at Buffalo, Buffalo, NY, USA

e-mail: cberman@buffalo.edu
} 
associated with many benefits, including physical and emotional well-being, coping with environmental stressors, and enhancing survival, both in humans (e.g., Cohen et al. 2015; Holt-Lunstad et al. 2010; House et al. 1988) and in nonhuman primates (e.g., Ostner and Schülke 2014; Sapolsky 2005; Schülke et al. 2010; Silk et al. 2003, 2010; Young et al. 2014).

The complexity of primate social systems may be captured by studying three interrelated aspects of social life-social organization, mating systems, and social structure (Clutton-Brock and Harvey 1977; Hinde 1976; Kappeler and Van Schaik 2002; Koenig et al. 2013; Thierry et al. 2004). Social organization refers to the distribution and composition of individuals within social groups, specifically group sizes, sex ratios, and sex-typical philopatry versus dispersal strategies (Clutton-Brock and Harvey 1977). Social organization in turn gives rise to the other two aspects of social life. The first concerns mating systems which can be seen as the outcome of individual reproductive strategies adopted by resident and dispersing adults in a group (Greenwood 1980). The second is social structure, which arises from the patterning and distribution of agonistic, affiliative, cooperative, and/or conflict-managing interactions among group members (Hinde 1976; Kappeler and Van Schaik 2002; Sterck et al. 1997; van Schaik 1989, 1996). Social structure is of particular interest to behavioral ecologists because it provides both opportunities and constraints on individuals as they strive to maximize the benefits of group living while minimizing its costs. As such, social structure provides a rich window for testing hypotheses about adaptive and evolutionary strategies that individuals may use to gain fitness.

Among primates, social structure varies widely. Over the years, several conceptual frameworks have been proposed to explain how ecological factors might explain this variation. Wrangham (1980) was one of the earliest socioecologists to point out that, in several cases, (1) species with similar social organizations display sharply different social structures and to (2) argue that the distribution and abundance of resources needed by females to reproduce influenced their tendencies to form groups and to disperse or not. He also introduced the idea that these factors would in turn influence within- and between-group agonistic and affiliative social structure. This approach was extended by van Schaik (1989) and by Sterck et al. (1997) to include predation pressure and infanticidal risk as influential ecological factors. Sterck et al. (1997) described variation in the social structure of diurnal primates (1) emphasizing the influence of competitive regimes within groups on the nature and quality of female relationships (despotic vs. tolerant vs. egalitarian) and (2) pointing out that dominance structures were often associated with other aspects of social structure, e.g., kin bias and coalitionary support (Sterck et al. 1997). Since then, researchers have continued to emphasize power relationships as central to understanding variation in social structure.

In contrast to socioecological explanations, other schools of thought argue that aspects of social structure are more strongly influenced by inherent or intrinsic characteristics (Thierry 2004, 2007). Dominance hierarchies are once again central to this framework (de Waal and Luttrell 1989), but rather than adaptive responses to current ecological conditions, they are hypothesized to be either due to ecological adaptation in the distant past (Chan 1996; Kamilar and Cooper 2015; Matsumura 1999) or to emergent properties of self-organizational processes (Hemelrijk 1999, 
2005; Puga and Sueur 2017). In either case, variation in social structure is posited to be strongly influenced by species' ancestral or phylogenetic histories (Balasubramaniam et al. 2012a; Kamilar and Cooper 2015; Thierry et al. 2008, 2000) due to tendencies for dominance structures to be structurally linked to entire suites of social traits and hence for these traits to covary with one another (Thierry et al. 2008; Thierry 2000). Such contrasting explanatory models have complicated our understanding of variation for dominance and other aspects of primate social structure.

In this chapter, we review our previous studies to illustrate the complexity of a few aspects of Tibetan macaque (Macaca thibetana) social structure, focusing on indicators of social style. The concept of social style posits that a suite of characteristics related to dominance and social tolerance covary (and may have coevolved) with one another and that species can be placed on a continuum ranging from extremely despotic to extremely tolerant (de Waal and Luttrell 1989; Thierry 2000, 2004; Thierry et al. 2008). Early studies on Tibetan macaques (Deng 1993; Ogawa 1995; Zhao 1996) detected a suite of moderately tolerant traits that led to their categorization as a "grade 3" species (Thierry 2000). Yet later work has revealed a mixture of characteristics that are associated with both despotism and tolerance, prompting a change in classification. Here we review this more recent line of evidence to describe how quasi-independent evolution, i.e., the apparent adaptive responses by animals to variation in current sociodemographic factors and ecological conditions, may have also influenced the evolution of such a mixture of social style traits in this species. We suggest that such effects may potentially mask underlying tendencies for the covariation of traits. Similarly, we describe comparative research across the macaque genus that suggests that aspects of social style may have been influenced by species' phylogenetic histories, by the covariation of traits to each other, and by adaptive responses to variation in current conditions. In doing so, we suggest that aspects of Tibetan social styles may represent flexible responses to different types of selection pressures that are nevertheless limited to a given speciestypical range of possible responses, i.e., "social reaction norms" (Berman and Thierry 2010). We end by highlighting some avenues for future research that address some crucial gaps in our current understanding of the evolution of Tibetan macaque social styles and macaque social structure in general.

\subsection{The Macaques and the Study of Variation in Social Structure}

To date, comparative studies of variation in primate social structure have largely focused on members of the family Cercopithecinae, specifically baboons (genus: Papio, Theropithecus) and macaques (genus: Macaca) (Cords 2013). This is because these genera are represented by many species that are among the most geographically widespread and ecologically diverse of all primates. Moreover, they show 
marked variation in several aspects of social structure both within and across species (Cords 2013). Members of the genus Macaca range from North Africa in the West to Japan in the East and from China in the North to Sulawesi, Indonesia, in the South (Abegg and Thierry 2002; Thierry 2013; Thierry et al. 2004). All macaque species show a broadly similar social organization (Thierry 2013; Thierry et al. 2004). Barring a few exceptions (Sinha et al. 2005), they live in multi-male, multi-female social groups with varying sex ratios (although usually skewed toward females). Females are philopatric and males disperse from their natal groups when they reach maturity (Cords 2013; Paul and Kuester 1987). Yet macaque species vary broadly in several aspects of social structure related to aggression intensity, dominance relationships, maternal style, tendencies to reconcile following conflicts, and tendencies to show preferences for kin in affiliative and cooperative exchanges (Thierry 2000, 2007, 2013).

Early observations found these various tendencies appeared to be clustered, particularly among some better-studied species. This led to the theoretical concept of macaque "dominance styles" (de Waal and Luttrell 1989) and shortly thereafter renamed "social styles" (Thierry 2000), a concept with dominance relationships at its core. The social style concept posits that aspects of macaque social structure covary with one another and that species can be placed on a continuum (later simplified into a four-grade scale) that ranges from extremely despotic to extremely tolerant (Thierry 2000, 2007; Thierry et al. 2004). Specifically, species categorized as "grade 1" [extremely despotic, e.g., rhesus macaques (Macaca mulatta) and Japanese macaques (M. fuscata)] and "grade 2" [moderately despotic, e.g., long-tailed macaques ( $M$. fascicularis) and pigtailed macaques ( $M$. nemestrina)] may be expected to show intense aggression, steep hierarchies and highly asymmetric dominance relationships (Balasubramaniam et al. 2012a), low tendencies to reconcile after conflicts (Thierry et al. 2008), strong preferences toward kin (Thierry et al. 2008), protective maternal styles (Thierry et al. 2000), and community formation or substructuring in their affiliative relationships (Sueur et al. 2011). In contrast, "grade 3" [moderately tolerant, e.g., Barbary macaques (M. sylvanus) and bonnet macaques (M. radiata)] and "grade 4" [extremely tolerant, e.g., crested macaques ( $M$. nigra) and Tonkean macaques (M. tonkeana)] species are hypothesized to display mild aggression, shallow hierarchies, frequent counter-aggression, strong tendencies to reconcile, l'ow degrees of kin bias, relaxed maternal styles, and dense wellconnected grooming social networks.

Although the concept of social style is widely employed in the primate literature, certain issues remain. First, the extent to which one can speak of single speciestypical social styles is not clear. In most Cercopithecine primates, female-female relationships define the core of the group's social structure (Cords 2013; Koenig et al. 2013; Sterck et al. 1997; van Schaik 1989). As such, most designations of social style among macaques are based on female-female relationships, particularly in captive groups where the number of males available to study is often limited (Balasubramaniam et al. 2012a, b; Thierry 2000; Thierry et al. 2004, 2008). However, a number of studies have found differences in social styles among males and 
females of the same species (Cooper and Bernstein 2008; Preuschoft et al. 1998; Richter et al. 2009; Tyrrell et al. 2018).

It is also unclear how consistent social style indicators are over time or among groups of the same species. Although several studies have found consistent styles among different captive groups (Demaria and Thierry 2001; Petit et al. 1997; Sueur et al. 2011; Thierry 1985), and among wild, free-ranging and captive groups of the same species (Balasubramaniam et al. 2012a, b), others have found variation in social style indicators (e.g., grooming kin bias, hierarchical steepness) as groups have grown and fissioned (Balasubramaniam et al. 2011; Berman and Thierry 2010; Zhang and Watanabe 2014). Such inconsistencies in the literature have been partly responsible for ongoing debates over the origins of social style and other aspects of social structure. Specifically, the extent to which variation in social structure may be linked to inherited characteristics [e.g., genetic polymorphisms, phylogenetic history (Blomberg et al. 2003; Thierry 2007, 2013; Thierry et al. 2000)] versus outcomes of adaptive responses of individuals to current socioecological factors (Clutton-Brock and Janson 2012; Isbell 2017; Koenig et al. 2013; Sterck et al. 1997) remains unclear and hotly debated.

Some proponents of the phylogenetic argument posit that aspects of macaque social style are structurally linked and hence covary with each other across species (Petit et al. 1997; Thierry 2000; Thierry et al. 2008). In an early extreme form, this idea, called the systematic variation hypothesis (Castles et al. 1996; Petit et al. 1997), posited that species that show a single indicator of a particular social style (e.g., steep dominance gradients in grade 1 species) may be expected to display all other aspects of that style. In other words, it predicts that all indicators for species showing extreme despotism or extreme tolerance should be in the extreme range and that all indicators for species showing intermediate styles should display intermediate indicators. However, there is now a consensus that this extent of covariation is not always detectable and may be different for different traits and species. For instance, Thierry et al. (2008) found that across the range of macaques with different social styles, post-conflict affiliation covaried systematically with explicit forms of contact, but not with grooming kin bias. Further, although most studies thus far have found the predicted clusters of social style indicators and marked differences between species at the extreme ends of the social style scale (e.g., Demaria and Thierry 2001; Sueur et al. 2011; Thierry 1985), the positions of species in intermediate grades remain unclear and do not always concur with the covariation hypothesis (summarized in Balasubramaniam et al. 2012b).

Many proponents of socioecological explanations for variation in social style hypothesize that current conditions such as the distribution and abundance of resources, predation pressure, and the risk of infanticide critically influence the number and spatial distribution of females in groups. In female philopatric groups, those factors in turn influence not only the number and distribution of males but also the social structure of the group. While social style indicators are expected to cluster to some extent, this framework (named the Ecological Model of Female Social Relationships or EMFSR: Koenig et al. 2013; Sterck et al. 1997) does not necessarily predict structural linkages or tight covariation among them. 
In the next sections, we summarize our research findings on aspects of Tibetan macaque social structure for both males and females. We describe indicators associated with both despotic and tolerant social styles and evaluate the extent to which these different indicators seem to covary with one another, or are labile, independent responses by individuals to external factors, within this species. Then, we review our comparative studies that examine the extent to which social style indicators covary and display phylogenetic signals and/or are influenced by variation in current sociodemographic factors, across macaque groups and species belonging to all four social style grades.

\subsection{Tibetan Macaques and the YA1 Group}

Tibetan macaques are the largest macaque species (Fooden 1986). Preferring montane habitats, they are found in the subtropical and temperate forests that range from South Central to Western China as far as Tibet (Li 1999; Zhao 1996). Taxonomically, they are in the sinica-arctoides phylogenetic clade. They are most closely related to Assamese (M. assamensis) and Arunachal (M. munzala) macaques (Balasubramaniam et al. 2012a; Chakraborty et al. 2007; Purvis 1995; Tosi et al. 2003), although they morphologically resemble stump-tailed macaques (M. arctoides). Like all macaques, they live in multi-male, multi-female social groups that show female philopatry, male dispersal, and linear dominance hierarchies (de Vries 1998; Zhao 1996).

Work on the ecology and social structure of Tibetan macaques began with pioneering studies on Mt. Emei, Sichuan Province, China (Deng 1993; Li 1999; Zhao 1996; Zhao et al. 1991), and at Mt. Huangshan, Anhui Province, China $\left(118.3^{\circ} \mathrm{E}, 30.2^{\circ} \mathrm{N}\right)(\mathrm{Li} 1999$; Wada et al. 1987). The study at Huangshan continued by focusing on the semi-provisioned Yulingkeng A1 or YA1 group (Li 1999). Huangshan is a popular tourist destination in East-Central China and home to several groups of Tibetan macaques with (apparently) nonoverlapping home ranges. The montane vegetation consists of mixed deciduous and evergreen forests at lower elevations and sparsely covered peaks at higher elevations (Li 1999; Zhao 1996; Zhao et al. 1991). The YA1 group has been monitored, and maternal kin relationships of adults have been recorded since 1986 ( $\mathrm{Li} 1999$ ). The data we review here were collected on the YA1 group over six observation periods spread across 12 years. During each of the six observation periods, the group's hierarchy was stable, and we used similar observation methods (focal animal sampling and all occurrences sampling). H. Ogawa collected data between 1991 and 1992, and C. Berman and colleagues collected data between 2000 and 2002. During this time, the group size varied from 39 to 52 individuals. Although wild, the macaques were managed for tourism for a period of time that overlapped with data collectioninconsistently during the first three periods, but consistently so for the second three periods. Park officials herded the animals from the forest into a viewing area where 
tourists could observe them from a pavilion, as the monkeys were provisioned with corn. Between feedings, the group spent most of their time in the surrounding forest.

\subsection{Evidence of Female Despotism Contradicts Earlier Studies}

When Thierry published his classic analysis of social style and proposed a fourgrade social style scale (Thierry 2000; Thierry et al. 2000), comprehensive analyses of core social style indicators were available for a limited number of macaque species. Hence, the placement of many species, including Tibetan macaques, was tentative and based on their phylogenetic closeness to better-studied species (Thierry et al. 2000), or on indirect behavioral indicators. Thierry (2000) placed Tibetan macaques in grade 3 (moderately tolerant) based on their membership in the sinicaarctoides lineage (which contains other tolerant macaques) and on early studies that described evidence for multiple traits that were associated with a mildly tolerant social style: frequent ritualized affiliation among males, bidirectionality in silent bare-teeth displays, triadic infant handling interactions particularly among males, and tolerant responses to infant handling by mothers (Deng 1993; Ogawa 1995; Zhao 1996). It was not until 2004 that Berman and colleagues evaluated multiple other core indicators of social style (Berman et al. 2004). Using data collected on the YA1 group between 2000 and 2002, this study expected to confirm the tentative designation of Tibetan macaques as "tolerant" or "grade 3" species. They examined (1) the degree of aggressive asymmetry and counter-aggression in dominance relationships, (2) conciliatory tendencies, and (3) kin bias in a variety of affiliative and tolerant behaviors separately for males and females.

The results were surprising for both sexes: they supported a despotic rather than a tolerant social style. First, both males and females displayed high degrees of asymmetry in their dominance relationships. Three indices were used to evaluate the extent to which aggression was bidirectional, specifically the (1) directional inconsistency index (or DII), (2) the dyads-up index, and (3) percentage of counter-aggression, and all revealed extreme aggressive asymmetry typical of extremely despotic species (Table 8.1). Similarly, submissive signaling in the form of silent bare-teeth displays was almost always given in the same direction between dyads and in the same direction as other fearful and submissive interactions. Second, conciliatory tendencies were low. These were examined using the post-conflict matched-control pairs, or the PC-MC method (de Waal and Yoshihara 1983), which examined the timing of affiliative interaction during a 5-min window of time following an act of aggression (the PC or post-conflict sample), and compared it with the timing during a comparable period of time without aggression (the $\mathrm{MC}$ or matched sample). The method thus evaluated whether affiliation occurred earlier, later, or at the same time in the $\mathrm{PC}$ as the $\mathrm{MC}$. The comparisons were used to calculate a corrected conciliatory tendency (CCT) that varies from 0 to $100 \%$ and 
Table 8.1 Bidirectionality of aggression during each of three data analysis periods ${ }^{\mathrm{a}}$ for a single group of Tibetan macaques

\begin{tabular}{l|l|l|l}
\hline & $8 / 1 / 00-1 / 28 / 01$ & $2 / 27 / 01-5 / 29 / 01$ & $12 / 9 / 01-7 / 25 / 02$ \\
\hline A. Directional inconsistency index & $3 / 583(5.2 \%)$ & $2 / 50(4.0 \%)$ & $2 / 108(1.9 \%)$ \\
\hline Male-male dyads & $6 / 160(3.8 \%)$ & $3 / 166(1.8 \%)$ & $4 / 243(1.6 \%)$ \\
\hline Female-female dyads & \multicolumn{5}{l}{} \\
\hline B. Dyads-up index & $1 / 36(2.8 \%)$ & $1 / 36(5.6 \%)$ & $0 / 28(0.0 \%)$ \\
\hline Male-male dyads & $3 / 78(3.8 \%)$ & $0 / 33(0.0 \%)$ & $0 / 45(0.0 \%)$ \\
\hline Female-female dyads & $3 / 37(8.1 \%)$ & $4 / 114(3.5 \%)$ & $6 / 157(3.8 \%)$ \\
\hline C. Percent counter-aggression
\end{tabular}

All three measures of bidirectionality indicate a high degree of asymmetry in dominance relationships among both males and females, typical of a despotic species

A. The percentage of total aggressive interactions that were directed in the less frequent direction within dyads

B. The percentage of dyads for which the main direction of aggression was up the dominance hierarchy

C. The percentage of instances of aggression of any kind to which the target responded with aggression of any kind

${ }^{a}$ Adapted from Berman et al. (2004)

Table 8.2 Kin bias among Tibetan macaques, indicated by Partial $\mathrm{Kr}$ coefficients between interaction rates and degree of relatedness, controlling for rank distance ${ }^{\mathrm{a}}$

\begin{tabular}{l|l|l|l|l|l}
\hline Partner combination & $\%$ Time w/in 5 m & Grooming & Sit near & Approaches & Co-feed \\
\hline$\phi-q$ & $0.16 *$ & $0.22 * *$ & $0.25 * *$ & $0.24 *$ & $0.18 *$ \\
\hline$\hat{\phi}-\hat{O}$ & -0.14 & 0.13 & $-0.17(*)$ & -0.17 & -0.14 \\
\hline
\end{tabular}

The results suggest a significant degree of kin bias among females in affiliation and tolerance

$* * p<0.01$

$* p<0.05$

$(*) p<0.1$

${ }^{\mathrm{a}}$ Adapted from Berman et al. (2004)

estimates the degree to which dyads are more likely to reconcile (i.e., engage in affiliation soon after a conflict than at other times) (Veenema et al. 1994). For female-female dyads, the conciliatory tendency was extremely low (4.2\%), a figure that is low even among grade 1 macaque species. For males, it was a moderate $19.7 \%$ (see also Berman et al. 2006), but still within the range of despotic male macaques (unrelated male Japanese macaques: Petit et al. 1997).

Finally, females, but not natal males, consistently displayed high levels of affiliative kin bias and social tolerance. Mean rates of female affiliation (grooming, sitting near, co-feeding) with maternal kin were significantly greater than affiliation rates with nonkin (Table 8.2). Indeed, the intensity of grooming kin bias, measured as the observed-to-expected ratio of grooming bouts between kin, suggested that females groomed kin more than three times the value expected by chance. All the results were consistent across seasons and locations (provisioning area vs. forest), 
strongly supporting a despotic social style for Tibetan macaques. Although several core indicators were similar to those of grade 1 macaques, findings from this study led to a reclassification of Tibetan macaques as grade 2 rather than grade 1 or grade 3 species (Matsumura 1999; Thierry 2007) based on previous findings of ritualized affiliative behavior among males and of maternal tolerance for infant handling among females.

Although these findings greatly expand our understanding of social style among Tibetan macaques, they pose complications for possible explanations for the origins of such despotism. On the one hand, a phylogenetic explanation is difficult since Tibetan macaques are members of the sinica-arctoides lineage which is composed of predominantly tolerant macaque species. Yet, they display heightened levels of despotism that are characteristic of members of the fascicularis lineage (Matsumura 1999; Thierry et al. 2000) like pigtailed macaques (Castles et al. 1996) and Assamese macaques (Cooper and Bernstein 2002). Socioecological explanations based on the distribution of natural resources and predation pressure are also unlikely given that Tibetan macaques have a largely folivorous diet (Zhao et al. 1991) and experience (historically) moderate levels of predation pressure (Xiong 1984), factors that socioecological frameworks associate with tolerant or egalitarian societies (Sterck et al. 1997).

Berman and colleagues (Berman et al. 2004) speculated that indicators of a despotic social style in this group may have risen recently due to human activity; activities associated with tourism, particularly range restriction, herding, and food provisioning, likely elevated levels of intragroup aggression and/or competition (Berman and Li 2002; Hill 1999; Judge 2000; Marechal et al. 2011; Ram et al. 2003) and thereby generated atypical despotism in a species that would otherwise show greater social tolerance. Together, these results demonstrate that, rather than all aspects of female social style showing moderate despotism, some are in the range of extremely despotic species, and others are in the range of moderately tolerant species. Such a mixture of both despotic and tolerant social style traits in the same species suggests that structural linkage and potential covariation of traits may be offset, at least in part, by potentially adaptive individual responses to contemporary selection pressures posed by human management.

\subsection{Males Exhibit Social Tolerance Despite Evidence for Despotism}

In general, less research has focused on male-male relationships than female-female relationships among Cercopithecine primates and other primates that display female philopatry and male dispersal. When males disperse, they typically join groups that lack close kin, particularly in species that disperse repeatedly (as do Tibetan macaque males, whose average tenure in a group is about 5-6 years: Berman et al., unpublished data). As such, opportunities for long-term affiliative and 
cooperative relationships among males are limited. More fundamentally, affiliation and cooperation would not be expected among males, because males primarily compete for resources (i.e., conceptions with fertile females) that cannot be shared in the same way as food patches or other resources (Schülke and Ostner 2008, 2013; Sterck et al. 1997). As such, theoretical considerations do not generally predict high levels of affiliation and cooperation among males.

Socioecological models predict that the social strategies of primate males are driven by the availability and distribution of fertile females (Kappeler and Van Schaik 2002; Sterck et al. 1997; van Schaik 1989). When several females form a cohesive group, single males are not likely to be able to monopolize them, particularly when they breed seasonally. This leads to the formation of multi-male, multifemale societies in which males may coexist but attempt to outcompete one another through various forms of scramble or contest competition, particularly over access to females (Kappeler 2000; van Schaik 1996; Van Schaik et al. 2004). High levels of competition should theoretically preclude strong male-male affiliative relationships in these groups. However, some macaque males regularly engage in affiliative interactions that lead to strong social bonds and that enhance their fitness (Ostner and Schülke 2014; Schülke et al. 2010; Young et al. 2014).

Indeed, contrary to predictions, particularly high levels of male-male affiliation and tolerance have been reported among groups and species with relatively even sex ratios versus those with highly female-biased sex ratios. In these cases, male-male affiliation and tolerance have been hypothesized to function as coping mechanisms against intense conflict and competition both from other group males (e.g., access to females, revolutionary coalitions) and from external threats (e.g., predators, intergroup encounters, dispersing males: Cooper and Bernstein 2002; Ogawa 1995; Preuschoft and Paul 2000). The reasoning is that cooperation with some males against others may enhance a male's competitive abilities within his group and that group action may increase probabilities of success against external threats.

Previous research on Tibetan macaques suggests that males compete vigorously with one another for rank and access to fertile females, consistent with a despotic social style (Li and Wang 1996). Nevertheless, as mentioned earlier, they also show several forms of affiliative interaction with one another, consistent with their tendencies toward relatively even sex ratios ( $\mathrm{Li} 1999$ ). These include moderate conciliatory tendencies, ritualized greetings, and bridging behavior in which infants are used to facilitate friendly contact between males and to enhance the chances of forming affiliative social bonds (Ogawa 1995).

To further examine the ways in which male Tibetan macaques may engage in tolerant and cooperative interactions with kin and nonkin, despite strong indications of a despotic social style, Berman and colleagues examined cooperative strategies among males, focusing particularly on agonistic coalitions (Berman et al. 2007). They examined affiliation, tolerance, and agonistic support to test the hypothesis that increased tolerance in otherwise despotic males may occur when high-ranking males require support from other males to maintain their positions. In this group, conservative coalitions, in which two higher-ranking males aggressively target a lowerranking male, are the most common, and these serve to reinforce the current 
hierarchy. Nevertheless, revolutionary coalitions in which two lower-ranking males challenge a higher-ranking male pose a threat particularly to alpha males. Although agonistic support is unrelated to kinship and rates of grooming, high-ranking males display tolerance in the form of co-feeding toward lower-ranking males that support them, and alpha males show the most cooperation with the males that targeted them in revolutionary coalitions. Berman and colleagues suggested that high-ranking males discourage revolutionary alliances by using two cooperative strategies. They primarily rely on conservative alliances, but also offer tolerance to potential rivals in cases in which conservative coalitions are less effective.

We suggest that, contrary to socioecological theory (van Hooff and van Schaik 1994; van Schaik 1996; Van Schaik et al. 2004), Tibetan macaque males may be "tolerant despots" ( $c f$ Kaburu and Newton-Fisher 2015). Just as Kaburu and Newton-Fisher use the term "egalitarian despots" to describe chimpanzees that display signs of social tolerance which emerge strategically from a more despotic dominance style, we suggest that social tolerance in male Tibetan macaques is not shaped by external factors like increased between-group competition or predation pressure which were low or absent in this population. Rather, we suggest that social tolerance may be an adaptive outgrowth of within-group despotism, in that it allows despotic males to enhance their competitive abilities by selectively displaying tolerance to other males. Like the findings for female social styles, findings for male-male relationships also suggest a mixture of both despotic and tolerant social style indicators. Such evidence for unlinked traits that may be independently influenced by different, sometimes opposing, types of selection pressures may mask or offset potential underlying evidence for the structural linkage or covariation of traits.

\subsection{Comparative Studies Provide Evidence for Both Covariation and Quasi-independent Evolution}

Comparative research among primate species provides powerful opportunities to discern the extent to which variation in a characteristic is likely to be related to variation in ecological factors and/or evolutionary trends (Nunn 2011). This is particularly the case for comparative studies of macaque social structure, given their similar social organizations but varying social structures (Thierry 2007). To date, comparative studies of macaque social structure have largely focused on evolutionary explanations, specifically on the influence of phylogenetic relatedness. However, they have found somewhat mixed evidence for the phylogenetic model. An early study found that 7 out of a set of 22 macaque social behavioral traits analyzed appeared to be strongly influenced by phylogenetic relatedness (Thierry et al. 2000). Later work found that aspects of macaque social structure related to post-conflict affiliation and explicit contact, but not grooming kin bias, were more similar among more closely related species and that they appeared to covary 
continuously across species in predicted directions after accounting for phylogeny (Thierry et al. 2008). Most of these studies focused on captive groups in which it was relatively easy to restrict the analysis to behavior outside of the feeding context and hence to avoid the possibility that behavior related to social style might be masked by direct feeding competition.

Building on these pioneering studies, Balasubramaniam et al. (2012a, b) conducted three comparative studies of variation in other aspects of macaque social structure, specifically dominance hierarchies and grooming social network structure, which until then had not been tested in a comparative framework that involved multiple macaque groups and species. These studies included both captive and freeliving groups of macaques, including Tibetan macaques at Huangshan, and specifically examined the potential influence of living condition on social style traits. We review the major findings from these three studies below, focusing on their implications for both the characterization of Tibetan macaque social style and for the evolutionary origins of macaque social structure in general.

In the first of two comparative studies of macaque dominance social structure that tested the predictions of phylogenetic models (Balasubramaniam et al. 2012a), Balasubramaniam and colleagues examined whether the steepness of hierarchies (de Vries et al. 2006) and degrees of dominance asymmetry or counter-aggression showed strong phylogenetic signals, i.e., whether they were more similar among more closely related species (Blomberg et al. 2003; Kamilar and Cooper 2015; Matsumura 1999; Thierry et al. 2008). They assembled a behavioral dataset on dyadic aggressive interactions and submissive displacements among adult females, for each of 14 groups of macaques representing 9 species. For each group, they calculated the steepness of the dominance hierarchy as the absolute slopes of plots between normalized David's scores (NDS: de Vries et al. 2006) and ordinal ranks of individuals attributed by David's scores. David's scores are calculated for each individual as the differences between its wins and losses in dyadic agonistic interactions, which are weighted by the relative wins and losses of all of the other individuals in the group (Gammell et al. 2003; de Vries et al. 2006). To date, hierarchical steepness represents the most comprehensive measure of the "dominance gradient" and hence the degree of despotism in the dominance hierarchy of a social group. In addition to steepness, they also calculated the degree of "dominance asymmetry," by estimating the proportion of aggressive interactions that involved counter-aggression from the initial recipient.

To test predictions of phylogenetic signals, they used multiple macaque Bayesian and maximum likelihood phylogenetic trees, both self-reconstructed and extracted from the online database for primate phylogenies 10kTrees (Arnold et al. 2010). The results were consistent with the phylogenetic model in that both hierarchical steepness and counter-aggression showed strong, significant phylogenetic signals. Moreover, phylogenetic signals were consistent and strong when they examined a subset dataset of just free-living groups representing seven species of macaques.

In a second comparative study that used the same dataset, Balasubramaniam et al. (2012b) tested the covariation hypothesis and found mixed support for it. They asked whether hierarchical steepness and counter-aggression both covaried with the 
hypothesized placement of species on Thierry's four-grade social style scale and whether evolutionary shifts in social style grade corresponded consistently to covariant changes in hierarchical steepness and counter-aggression. As predicted by the covariation hypothesis, steepness and counter-aggression were strongly correlated with the placement of species on macaque social style scales in the predicted directions. Yet the nature of these relationships differed for each trait. On the one hand, hierarchical steepness appeared to covary continuously with the scale. Macaques in grades 1 and 2, including Tibetan macaques, showed the steepest hierarchies, grade 3 species showed moderately steep hierarchies, and grade 4 species showed the shallowest hierarchies. On the other hand, counter-aggression appeared highly dichotomous. Species from grades 1-3 all showed similar and markedly low levels of counter-aggression (range, $0.6-6.4 \%$ of all aggressive interactions) in comparison with the two grade 4 species (crested macaques, $50.8 \%$ of aggressive interactions; Tonkean macaques, $60.4 \%$ ). This suggested that the covariation between dominance traits and social scale were driven primarily by species at the extreme ends of the scale (grade 1 vs. grade 4 macaques).

In comparison, the characteristics of species in intermediate grades 2 and 3 were inconsistent. For instance, grade 1 rhesus and Japanese macaques showed both steep dominance hierarchies (range, 0.68-0.99) and low levels of counter-aggression (range, $0-7.1 \%$ of all aggressive interactions), while grade 4 Sulawesi crested and Tonkean macaques showed the opposite characteristics (steepness range, 0.27-0.53; counter-aggression range, $50-61 \%$ of all aggressive interactions). However, grade 2 species, rather than showing more shallow hierarchies than grade 1 , fell within the range for grade 1 species (steepness range, $0.85-0.98$ ). In fact, two grade 2 speciesTibetan and long-tailed macaques-showed the steepest hierarchies of all species examined in the study, i.e., exceeding the values for grade 1 Japanese and rhesus macaques. Further, Tibetan macaques showed the lowest levels of counteraggression (mean $=0.64 \%$; range, $0.53-0.76 \%$ of all aggressive interactions), even lower than grade 1 macaques.

The case of grade 3 macaques was even less consistent. Although hierarchical steepness of Barbary macaques was intermediate to those for grades 2 and 4 as predicted for a moderately tolerant social style, low levels of counter-aggression seen in this same group were more indicative of a more despotic style (but see Thierry and Aureli 2006), indicating possible evidence for quasi-independent evolution. Moreover, grade 3 bonnet macaques showed both steeper hierarchies and low levels of counter-aggression, within the range of despotic species.

To test the covariation hypothesis statistically, Balasubramaniam et al. (2012b) used phylogenetic independent contrast approaches of ancestral trait reconstruction to determine whether major evolutionary shifts from despotic to tolerant social style grades corresponded to shifts in hierarchical steepness and counter-aggression in the evolutionary history of macaques. The findings were telling. For both steepness and counter-aggression, the magnitudes of independent contrasts were greatest at the nodes in the phylogenetic tree that split grade 4 macaques from all other grades. This was consistent with the finding that there were indeed marked differences between macaques at the extreme ends of the scale. However, contrary to predictions, 
evolutionary shifts from higher to lower social style scales, or from tolerant to despotic societies, did not result in consistent increases in steepness contrasts or decreases in counter-aggression contrasts. Moreover, the magnitude of steepness and counter-aggression contrasts were no greater at nodes in the phylogeny where there were evolutionary shifts in social style, compared to "neutral" nodes in which there were no shifts in style. In summary, the authors found strong evidence for phylogenetic signals in dominance traits and mixed evidence for the covariation hypothesis. Specifically, covariation seemed to more strongly influence the underlying differences in dominance hierarchies between some species and phyletic lineages (macaques across grades 1 and 4), but less so others (species in grades 2 and 3).

In a third study, Balasubramaniam and colleagues (2018a) examined interspecific covariation in higher-order aspects of both dominance hierarchies and social grooming relationships across an even wider range of macaque populations. To capture higher-order aspects of social structure, they used social network analysis (SNA: Farine and Whitehead 2015; Lusseau 2003). Beyond using only direct interactions among dyads, network approaches incorporate both the direct social connections and indirect pathways of interactions among individuals (Brent et al. 2011; Farine and Whitehead 2015; Kasper and Voelkl 2009; Sueur et al. 2011). Such approaches may identify consistent patterns or "motifs" of interactions that in turn describe group social structure. The focus on social grooming, a core aspect of affiliative and cooperative social structure, expanded on previous studies that had predominantly focused on aspects of post-conflict affiliation, affiliative kin bias, and dominance hierarchies (but see the inclusion of macaque grooming traits by Schino and Aureli (2008) in their interspecies analyses).

In comparison to these latter traits which may be strongly influenced by intrinsic factors such as personality (Capitanio 1999; Krause et al. 2010), matrilineal inheritance (Cords 2013; Kapsalis 2004; Sade 1972), and phylogenetic histories (Thierry 2007; Thierry et al. 2008, 2000), the patterning and distribution of grooming relationships has been assumed to be more responsive to environmental variability, such as group sizes (Berman and Thierry 2010; Kasper and Voelkl 2009; Majolo et al. 2009), the presence of infants (Fruteau et al. 2011; Gumert 2007; Henzi and Barrett 2002; Tiddi et al. 2010), and the distribution of resources (Balasubramaniam and Berman 2017; Carne et al. 2011; Ventura et al. 2006). Nevertheless, across the macaque genus, the structure of grooming social networks is also likely to be strongly influenced by varying tendencies for species to affiliate with kin, i.e., grooming kin bias (Berman 2011; Berman and Kapsalis 2009; Berman and Thierry 2010; Kapsalis 2004; Thierry et al. 2008).

Under the covariation framework, more despotic, nepotistic species that show steeper dominance hierarchies, and in which individuals prefer to interact more with close kin compared to distant kin, may be expected to show more modular or substructured grooming networks (Sueur et al. 2011). On the other hand, more tolerant species in which hierarchies are shallower, and in which individuals form affiliative relationships with a wider range of conspecifics, may be expected to show more dense, well-connected social networks that are less modular (Sueur et al. 2011). In support of this covariation framework, a study by Sueur and colleagues 
found that more intolerant or nepotistic grade 1 species like rhesus and Japanese macaques showed less dense but more centralized, modular, or substructured social networks than more socially tolerant, less nepotistic grade 4 species like Tonkean and Sulawesi crested macaques (Sueur et al. 2011). Balasubramaniam and colleagues used a wider range of macaques to ask whether (1) aspects of dominance and grooming social networks showed strong phylogenetic signals and (2) they covaried with each other independently of the effects of phylogeny and/or extrinsic sociodemographic factors like group size, sex ratio, and living condition.

The authors assembled a broad comparative dataset-38 dominance matrices and 34 datasets of social grooming-from captive, free-ranging, and wild groups representing 10 species of macaques. From these, they estimated two dominance social network traits, specifically triangle transitivity (Shizuka and Mcdonald 2012) and group-wide dominance certainty (Fujii et al. 2013). From the grooming datasets, they estimated three aspects of grooming social network structure: the (1) centrality coefficient, i.e., the extent to which dominant individuals are also highly central in their grooming network (Handcock et al. 2006); (2) Newman's modularity, i.e., the degree to which networks were substructured into communities of closely interacting individuals (Newman and Girvan 2004); and (3) clustering coefficient (Csardi and Nepusz 2006), which is an indicator of the localized density of a group's social connections. As in previous efforts, they replicated their comparative analyses across multiple phylogenetic trees to account for phylogenetic branch length uncertainty.

As in the previous comparative studies, the results showed mixed evidence for the phylogenetic model. Consistent with findings from the previous study on dominance steepness and counter-aggression (Balasubramaniam et al. 2012a, b), dominance transitivity and certainty both showed strong phylogenetic signals (Fig. 8.1). On the other hand, aspects of grooming social networks showed only moderate or weak phylogenetic signals (Fig. 8.1). Moreover, contrary to the covariation hypothesis, grooming network measures did not covary with dominance traits across species (Fig. 8.2). Instead, two aspects of grooming social networks, modularity and clustering coefficient, were more strongly predicted by group size, a sociodemographic factor, than by species' social styles or dominance traits. Specifically, larger groups of macaques showed more modular, less densely clustered grooming networks than smaller groups, with the results being independent of groups' living condition and variation in sampling effort.

Taken together, findings from these interspecies comparative studies suggest that different aspects of social structure may have been subject to different evolutionary and ecological selection pressures. Specifically, aspects of dominance social structure seem to be strongly influenced by phylogenetic relationships and to show tendencies to covary across some (but not all) species and lineages. In comparison to dominance, grooming social networks seem weakly influenced by phylogeny. Rather than covarying with dominance traits across groups and species, grooming networks appear to be more responsive to variation in current sociodemographic factors like group sizes and living condition. The detection of more clear-cut differences in dominance traits between the grade 4 Sulawesi macaques and members of grades 1 and 2 in the fascicularis lineage suggests that the influence of 


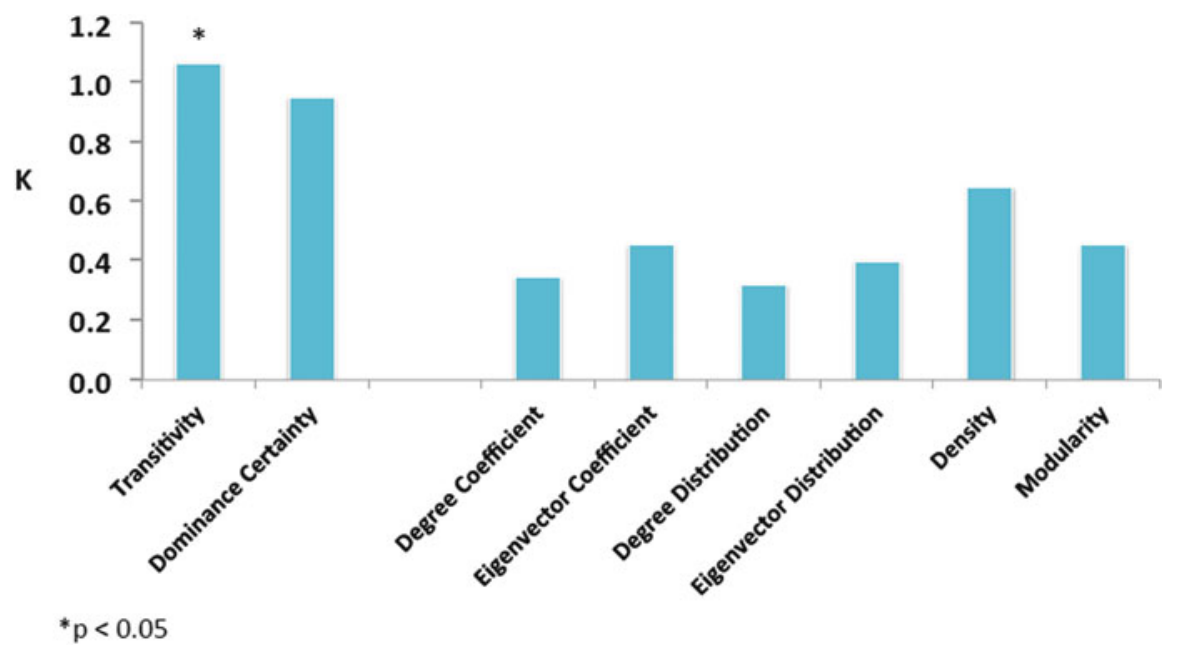

Fig. 8.1 Bar plot of the $K$-statistic calculated to determine the strength of phylogenetic signals among aspects of dominance and grooming social network structure for ten species of macaques. On the one hand, values of $K$ approaching or greater than 1 indicate strong phylogenetic signals in the dominance traits. On the other hand, values of $K<1$ indicate moderate-to-weak signals in the grooming traits

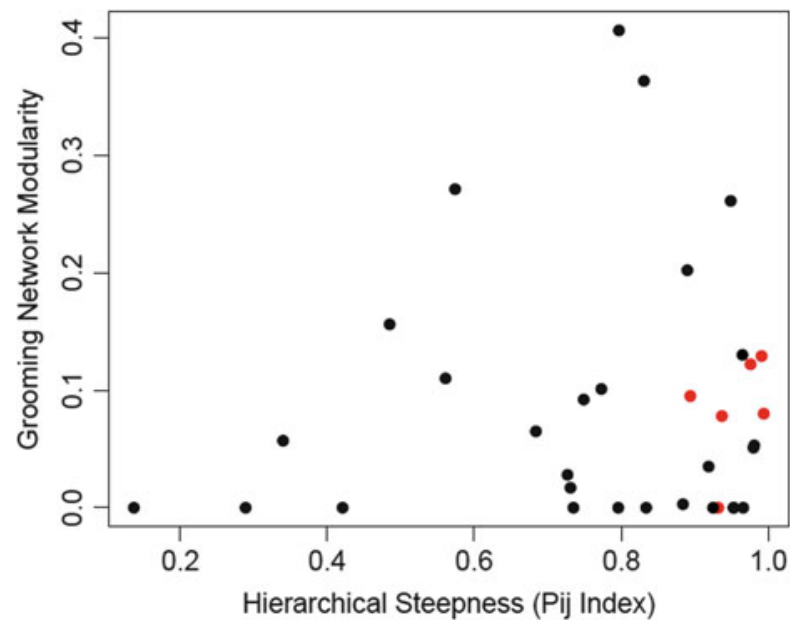

Fig. 8.2 Scatterplot showing the lack of a relationship between directional consistency index (DCI) of dominance hierarchies and Newman's community modularity of grooming social networks for 34 groups of macaques across 10 species. Red dots represent scores for the YA1 Tibetan macaque group at each of six study periods

phylogeny and the structural linkage of traits may be visible across higher organizational scales (e.g., across some species and lineages), but perhaps less so at lower organizational scales (e.g., across species within a lineage, across groups). In other 
words, they suggest that the structural covariation of aspects of macaque social structure has occurred over longer evolutionary timescales that separate entire phylogenetic lineages, rather than across shorter timescales that separate species or populations within lineages.

Consistent with findings at the interspecific level, and indeed with the conclusions from the other within-species studies we have reviewed above, we also found a lack of evidence for intraspecific covariation between dominance and grooming social structure among just Tibetan macaques. They displayed moderate-to-steep dominance hierarchies and very low levels of counter-aggression on the one hand and moderate-to-low levels of grooming modularity on the other hand. Moreover, aspects of dominance hierarchies in Tibetan macaques were not correlated with aspects of grooming social network across six study periods of hierarchical stability (e.g., hierarchical steepness vs. grooming modularity: $n=6, r=0.26, p=0.62$ ). Thus, findings from our comparative studies are consistent with those from our previous studies on just Tibetan macaques. Both suggest that aspects of Tibetan macaque social style, while having potentially been shaped by phylogenetic relatedness and structural linkage in the evolutionary past, have been subject to somewhat unlinked, independent trajectories influenced by current socioecological and demographic conditions more recently in their evolutionary history.

\subsection{Discussion and Future Directions}

Aspects of social structure represent higher-order phenomena, i.e., phenotypically visible, group level outcomes of individuals striving to access the benefits of group living while minimizing its costs. Given the importance of social structure for individual fitness, primatologists are interested in the evolutionary underpinnings of variation in social structure (Clutton-Brock and Janson 2012; Koenig et al. 2013; Thierry 2004). Theoretical models based on species' phylogenetic history (Matsumura 1999; Thierry 2007; Thierry et al. 2000), inherent self-organization by individuals (Hemelrijk 1999, 2005; Puga and Sueur 2017), and adaptations to variation in current ecological conditions (Kappeler and Van Schaik 2002; Sterck et al. 1997; van Schaik 1989) have all been proposed, but currently there is no consensus regarding the relative extents to which these factors influence social structure.

In this chapter, we demonstrate how research on the genus Macaca, and in particular on Tibetan macaques, has provided useful empirical tests of some of these conflicting frameworks. Among macaque researchers, some proponents of phylogenetic arguments argued that aspects of social structure, specifically those that constitute social style, are structurally linked and covariant with each other (Petit et al. 1997; Thierry 2000; Thierry et al. 2008). Citing the detection of strong phylogenetic signals in some core aspects of macaque social style, they predicted that evolutionary change in one trait would co-occur with evolutionary change in a suite of other traits, with such covariation being more perceptible between species rather than within groups of the same species (Petit et al. 1997; Thierry 2000; Thierry et al. 2008). 
Our findings on Tibetan macaques, and from comparative studies across a range of macaques, reveal incomplete evidence for such covariation across species and social style traits. We suggest that the pattern of covariation (and the lack thereof) that we found is consistent with the notion suggesting that covariation was likely present in the evolutionary past of the genus but that it has been subsequently partially offset by more contemporary, quasi-independent responses by macaques to variation in current conditions.

First, we found a mixture of both despotic and tolerant social style traits in Tibetan macaques. While aspects of the dominance structure in Tibetan macaques are within the range of despotic macaques, the structure of affiliative grooming social networks, male-male ritualized affiliation, and cooperative exchange are all characteristic of more tolerant societies. Covariation by itself, i.e., that has not been influenced by adaptive responses, would have been suggested if all these characteristics had showed moderate despotism or moderate tolerance. Second, our comparative studies revealed evidence for covariation between dominance traits and social style grade across some macaques in different phylogenetic lineages, but not across species within the same lineage. Third, the finding that grooming social network structure was more strongly influenced by group size than by phylogeny and dominance traits suggests that covariation was apparently offset by adaptive responses by macaques more recently in their evolutionary history. In other words, different aspects of social style and social structure in general likely evolved along more independent evolutionary trajectories, with some traits more strongly influenced by past ancestry and structural linkage than others, and others apparently more labile to current conditions.

This view is consistent with the concept of "social reaction norms," or the idea that species may respond similarly to major ecological changes, but may have inherently different ranges of responses to the same conditions, i.e., ranges that are related at least in part to their ancestry (Berman and Thierry 2010). The concept of social reaction norms can be seen as a group-level analog of the concept of interindividual variation in "behavioral syndromes," in which suites of correlated behaviors reflect individual variation in behavioral plasticity and in individual's capacities to show adaptive responses across multiple environmental situations and contexts (Sih et al. 2004, 2012).

Having said that, there remain many gaps in our understanding of social style and social structure in general in Tibetan macaques and in the macaque genus as a whole. Social style indicators have yet to be examined in many species, and a number of additional hypotheses about their origins remain to be explored in detail. We end this chapter by proposing and elaborating on five potentially important avenues of future research on social styles.

Paternal Kin Relatedness In animal social groups, the relatedness of individuals is strongly associated with the form, frequency, and distribution of cooperative and competitive social interactions (Hamilton 1964). In most Cercopithecine primates, females are philopatric, and there is ample evidence that matrilineal kin bias structures many aspects of social behavior within groups, more so in despotic species than tolerant species (Berman 2011; Berman and Thierry 2010; Thierry 2007; Thierry et al. 2008). As such, maternal kin bias has been considered one of the core 
indicators of a group's social style (Thierry 2000). In 1979, Altmann suggested that in addition to matrilineal ties, the structure of within-group relatedness may also be influenced by mating patterns, specifically by the degree to which individual males are able to monopolize fertile females (Altmann 1979). Specifically, the frequent replacement of highly successful males (i.e., males with high reproductive skew) may lead to age-structured paternal sibships within groups. If this occurs, and if individuals are able to recognize their paternal kin, inherent tendencies to favor kin could influence the patterning and distribution of cooperative and competitive interactions in a group and hence aspects of social style (Widdig 2013).

Recently, Schülke and Ostner hypothesized that the evolution of social tolerance in some macaque species may in fact be explained by high male reproductive skew (Schülke and Ostner 2008, 2013). High mean levels of paternal relatedness might explain why females in tolerant species distribute their affiliative interactions across a wide range of partners. As evidence for this hypothesis, they found that species of macaques classified as less nepotistic and more tolerant also showed higher male reproductive skew (Schülke and Ostner 2008). However, their analyses were limited by a small sample size and to comparisons of intolerant but seasonally breeding macaques with tolerant but nonseasonal macaques and hence were unable to control for the effects of seasonality on reproductive skew. In a second study, they found that paternal kin bias accounted for a small but significant proportion of the variation in the strength of grooming social bonds in a captive group of rhesus macaques (Schülke et al. 2013). Whether the reproductive skew argument can help explain some or all of the indicators of tolerance in Tibetan macaques is uncertain. Although male mating success is highly skewed toward dominants and alpha males have tenures of only a year or two, whether or not this translates into reproductive skew awaits genetic confirmation of paternity. Also needed are broader comparative studies that assess possible links between male reproductive skew, paternal relatedness, and multiple aspects of female social structure.

Disease Risk as a Selection Pressure Traditional socioecological models have speculated that multiple socioecological factors-natural resource abundance, clumped, human provisioned food, and changes in predation pressure over evolutionary time-may have all impacted variation in primate social structure (Kappeler and Van Schaik 2002; Sterck et al. 1997; van Schaik 1989). More recently, the influence of another ecological factor-disease risk-has also been proposed (Kappeler et al. 2015; Nunn 2012), but it has remained relatively understudied. Disease risk may influence primate group living and social life in at least two ways. First, strong parasite prevalence may encourage more spatially widespread social groups and subgrouping because it minimizes parasite transmission through social contact (Kappeler et al. 2015; Nunn 2012; Nunn et al. 2011). Indeed, comparative studies across a range of primates have found strong, positive correlations between parasite prevalence or diversity and community substructuring or modularity of affiliative social networks (Griffin and Nunn 2012; Nunn et al. 2015). This relationship is consistent with the hypothesis that increased parasite risk may have led to the evolution of increased levels of despotism in some primate groups and species, 
especially given that modular social networks have already been shown to be a characteristic of such societies (Sueur et al. 2011).

On the other hand, increased parasite risk may also cause animals to seek out more social partners, because strong and diverse social ties may enhance their social capital and lower stress levels associated with decreased disease resistance (Cohen et al. 2007; Kaplan et al. 1991; Sapolsky 2005). In accordance with this "social buffering hypothesis," increased disease risk could lead to the evolution of greater social tolerance (Silk et al. 2003, 2010; Young et al. 2014).

Evidence from macaque species, particularly wild Japanese macaques (MacIntosh et al. 2012; Romano et al. 2016) and captive rhesus macaques (Balasubramaniam et al. 2016, 2018b), suggests the transmission of gastrointestinal nematode parasites and gut pathogenic bacteria, respectively, maybe strongly influenced by the structure of affiliative grooming or huddling social networks. However, at this time, no comparable data are available for Tibetan macaques. Nevertheless, given the now well-established impact that parasite risk has on aspects of primate sociality and health (Kappeler et al. 2015), future research should focus on further unraveling such links.

Intraspecific Variation In general, comparative studies of variation in primate social organization and social structure have tended to focus more on interspecific than intraspecific variation, with the latter often overlooked or not appropriately accounted for (Clutton-Brock and Janson 2012; Nunn 2011). Given this, a long-term goal of Tibetan macaque research should be to establish the ecological and evolutionary underpinnings of intraspecific variation in social structure. To date, much of our understanding of intraspecific variation in Tibetan macaque social structure stems from longitudinal data collected on a single group at Mt. Huangshan. In one study, Berman and colleagues found that the extent of grooming kin bias among females in YA1 varied across seven different data collection periods between December 1991 and November 2004 (Berman et al. 2008). This variation was positively correlated to group size, but unaffected by other socioecological factors (e.g., within-group competition, human presence), leading to speculation that increased time constraints faced by the macaques when the group size is larger may influence their social styles (Berman et al. 2008). Later, Balasubramaniam and colleagues revealed that the steepness of the dominance hierarchy of YA1 females also varied significantly across six of these periods (Balasubramaniam et al. 2011). Yet contrary to expectation, steepness was negatively correlated to group size, leading to the speculation that the macaques responded to human presence by forming within-group alliances that may in turn have impacted their dominance style. So whether and how socioecological factors may impact one or more aspects of Tibetan macaque social structure remains unclear.

Given that the social groups studied at both Mt. Huangshan and Mt. Emei were subjected to varying degrees of tourism, provisioning, and range restriction (Berman and Li 2002), comparisons of their social styles with each other and with those of other wild populations are crucial. Evidence for intergroup differences in aspects of social structure is available for other free-living macaque species, but somewhat 
mixed. For instance, Majolo et al. (2009) found stark intergroup differences in the distribution of grooming and post-conflict reconciliation between two wild Japanese macaque groups of different sizes within the same population. Further, Duboscq et al. (2013) found between-group differences in rates of approaches, silent bareteeth displays, and percentages of counter-aggression by females in two groups of wild crested macaques at Tangkoko Nature Reserve. On the other hand, a study on free-ranging rhesus macaques at Cayo Santiago revealed no differences in female dominance hierarchies, aggression intensities, and post-conflict affiliation rates across three groups of different sizes (Balasubramaniam et al. 2014). Such findings warrant establishing potential links (or the lack thereof) between socioecological factors and intraspecific variation in social structure across groups and populations of Tibetan macaques as well as other species.

Comparative Studies of Male Social Styles Most of what we know about the concept of macaque social styles has emerged from studies of female-female social relationships in captive groups. In comparison, the social relationships of males have been less intensely studied, with studies on free-ranging and wild populations of some species having just emerged during the last decade. In the light of this, we suggest that the time is right for conducting comparative studies of the evolution of male social styles.

Male relationships among the female philopatric Cercopithecine primates are expected to be predominantly intolerant or antagonistic. Coalitions are expected to be primarily (1) conservative to maintain dominance rank and (2) based on partner availability rather than the establishment of long-term affiliative social bonds among unrelated males (Cords 2013; Kappeler 2000; Preuschoft and Paul 2000). Yet, there is also evidence for overt affiliation, social bond investment, and male-male social tolerance in some species (Ostner and Schülke 2014; Schülke et al. 2010), including Tibetan macaques (see above). Evolutionary explanations for such evidence remain somewhat unclear. One possible explanation, proposed above for Tibetan macaques, involves the emergence of male "tolerant despots," i.e., the idea that male social tolerance may be an emergent outcome of a group- or species-typical tendency to exhibit a generally despotic social style. This may occur when selective tolerance enhances males' abilities to compete in a despotic society. Such indicators of social tolerance maybe a consequence of males' counter-strategies to deal with generally heightened levels of within-group resource competition (Ostner and Schülke 2014; Schülke et al. 2010).

Findings from Assamese macaques also seem to support this explanation. For instance, both male and female Assamese macaques show steep, linear dominance hierarchies that are indicative of high within-group competition and a despotic social style (Balasubramaniam et al. 2012a, b; Cooper 1999; Cooper and Bernstein 2002, 2008). Yet, males also show moderate levels of post-conflict affiliation (Cooper 1999; Cooper and Bernstein 2002, 2008) and form long-term social bonds based on partner preference rather than partner availability (Kalbitz et al. 2016; Ostner and Schülke 2014; Schülke et al. 2010). Findings from other species suggest that male social tolerance, rather than being emergent outcomes of within-group despotism, 
may have socioecological underpinnings. For instance, grooming and alliance formation among male Japanese macaques appear to be more strongly influenced by between-group mating competition than by within-group competition (Horiuchi 2007). In bonnet macaques, the distribution and abundance of natural resources may strongly influence male-to-female sex ratios and, thereby, male social strategies (Ram et al. 2003; Sinha et al. 2005).

When abundant and widespread resources give rise to large, multi-male-multifemale groups with near-even adult sex ratios, reduced within-group competition may give rise to unusual levels of social tolerance, ritualized greetings, huddling, and social grooming among males (Adiseshan et al. 2011; Silk 1994, 1999). When resources are clumped or seasonal, intense female-female competition may lead to group-fissioning, resulting in the emergence of atypical unimale troops in several species (Ram et al. 2003; Sinha et al. 2005). In these contexts, males actively herd females, defend them against immigrating males by engaging in intergroup encounters, and remain intolerant of resident juvenile and subadult males (Ram et al. 2003; Sinha et al. 2005). Such stark differences and explanations for male social strategies warrant more comparative studies across macaque species that examine the relative effect(s) of intrinsic characteristics (e.g., female social styles, male despotism) and extrinsic factors (e.g., resource abundance, intergroup competition, predation) on male social styles.

Phylogeographic Approaches Finally, comparative studies have now established that several (but not all) aspects of macaque social structure (Balasubramaniam et al. 2012a, 2018a; Thierry et al. 2008), and more broadly primate sociality (Kamilar and Cooper 2015), are associated at least in part with species' ancestral relationships. What is unclear is whether such phylogenetic signals are reflections of true genetic linkage or coevolution versus artifacts of adaptive responses by ancestral species to major environmental changes (Balasubramaniam et al. 2018a). To address this gap, we recommend that future research should focus on establishing links between ancestral state reconstructions of primate social structure (Pagel et al. 2004; Revell 2012) and potential changes in historic phylogeographic ranges (Abegg and Thierry 2002; Lemey et al. 2009; Ree and Smith 2008). Such approaches would help establish whether, for instance, some aspects of social structure coevolved with major dispersal events or climatic changes toward more resource abundant (or sparser) environments in the evolutionary past.

Acknowledgments We thank the Huangshan Monkey Management Center and the Huangshan Garden Forest Bureau for granting permission to collect field data on the YA1 Tibetan macaque group. We thank the following organizations: the Leakey Foundation, the Wenner-Gren Foundation, and the National Geographic Society (C.M.B.); the National Natural Science Foundation of China, Key Teacher Program of the Ministry of Education of China, and the Excellent Youth Foundation of Anhui (J.L.) for providing funding to carry out fieldwork at Huangshan. We are grateful to May Lee Gong, Krista Jones, Ming Li, Stephan Menu, Stephanie Pieddesaux, Justin Sloan, and Lei Zhang for their role as field assistants at Huangshan. We give special thanks to Xinming Chen and his family for housing and accommodation in China. For the comparative studies, we thank several past and current colleagues in primatology and their research teams, specifically Marina Butovskaya, Matthew Cooper, Arianna De Marco, Julie Duboscq, Sabina 
Koirala, Bonaventura Majolo, Andrew MacIntosh, Richard MacFarland, Sandra Molesti, Odile Petit, Gabriele Schino, Sebastian Sosa, Cedric Sueur, Bernard Thierry, and Frans de Waal for contributing their datasets and playing a role in manuscript publication. Further, we also thank Katharina Dittmar, Brenda McCowan, and Brianne Beisner for providing much-needed input in phylogenetic and social network analyses, respectively. We thank the National Science Foundation (NSF), USA, for partially funding the comparative studies. Finally, we are grateful to Bernard Thierry and Bonaventura Majolo for their reviews and feedback while constructing this chapter.

\section{References}

Abegg C, Thierry B (2002) Macaque evolution and dispersal in insular south-east Asia. Biol J Linn Soc 75(4):555-576

Adiseshan A, Adiseshan T, Isbell LA (2011) Affiliative relationships and reciprocity among adult male bonnet macaques (Macaca radiata) at Arunachala Hill, India. Am J Primatol 73:1107-1113

Altmann J (1979) Age cohorts as paternal sibships. Behav Ecol Sociobiol 6:161-164

Arnold C, Matthews LJ, Nunn CL (2010) The 10kTrees website: a new online resource for primate phylogeny. Evol Anthropol 19:114-118

Balasubramaniam KN, Berman CM (2017) Grooming exchange for resource tolerance: biological markets principles in a group of free-ranging rhesus macaques. Behaviour 154(11):1145-1176

Balasubramaniam KN, Berman CM, Ogawa H, Li J (2011) Using biological markets principles to examine patterns of grooming exchange in Macaca thibetana. Am J Primatol 73 (12):1269-1279

Balasubramaniam KN, Dittmar K, Berman CM, Butovskaya M, Cooper MA, Majolo B, Ogawa H, Schino G, Thierry B, de Waal FBM (2012a) Hierarchical steepness and phylogenetic models: phylogenetic signals in Macaca. Anim Behav 83:1207-1218

Balasubramaniam KN, Dittmar K, Berman CM, Butovskaya M, Cooper MA, Majolo B, Ogawa H, Schino G, Thierry B, de Waal FBM (2012b) Hierarchical steepness, counter-aggression, and macaque social style scale. Am J Primatol 74:915-925

Balasubramaniam KN, Dunayer ES, Gilhooly LJ, Rosenfield KA, Berman CM (2014) Group size, contest competition, and social structure in Cayo Santiago rhesus macaques. Behaviour 151:1759-1798

Balasubramaniam KN, Beisner BA, Vandeleest J, Atwill ER, McCowan B (2016) Social buffering and contact transmission: network connections have beneficial and detrimental effects on Shigella infection risk among captive rhesus macaques. PeerJ 4:e2630

Balasubramaniam KN, Beisner BA, Berman CM, De Marco A, Duboscq J, Koirala S, Majolo B, MacIntosh AJJ, McFarland R, Molesti S, Ogawa H, Petit O, Schino G, Sosa S, Sueur C, Thierry B, de Waal FBM, McCowan BJ (2018a) The influence of phylogeny, social style, and sociodemographic factors on macaque social network structure. Am J Primatol 80(1): e227227

Balasubramaniam KN, Beisner BA, Guan J, Vandeleest J, Fushing H, Atwill ER, McCowan B (2018b) Social network community structure is associated with the sharing of commensal E. coli among captive rhesus macaques (Macaca mulatta). PeerJ 6:e4271

Berman CM (2011) Kinship: family ties and social behavior. In: Campbell CJ, Fuentes A, MacKinnon KC, Panger M, Bearder SK (eds) Primates in perspective, 2nd edn. Oxford University Press, New York, pp 576-587

Berman CM, Kapsalis E (2009) Variation over time in grooming kin bias among female rhesus macaques on Cayo Santiago supports the time constraints hypothesis. Am J Phys Anthropol 48:89-90 
Berman CM, Li J (2002) Impact of translocation, provisioning and range restriction on a group of Macaca thibetana. Int J Primatol 23:287-293

Berman CM, Thierry B (2010) Variation in kin bias: species differences and time constraints in macaques. Behaviour 147(13):1863-1887

Berman CM, Ionica CS, Li J (2004) Dominance style among Macaca thibetana on Mt. Huangshan, China. Int J Primatol 25:1283-1312

Berman CM, Ionica CS, Dorner M, Li JH (2006) Post-conflict affiliation between former opponents in Macaca thibetana: for males only? Int J Primatol 27:827-854

Berman CM, Ionica CS, Li J (2007) Supportive and tolerant relationships among male Tibetan macaques at Huangshan, China. Behaviour 144:631-661

Berman CM, Ogawa H, Ionica CS, Yin H, Li J (2008) Variation in kin bias over time in a group of Tibetan macaques at Huangshan: contest competition, time constraints or stress response? Behaviour 145:863-896

Blomberg SP, Garland T, Ives A (2003) Testing for phylogenetic signal in comparative data: behavioral traits are more labile. Evolution 57:717-745

Brent LJN, Lehmann J, Ramos-Fernandez G (2011) Social network analysis in the study of nonhuman primates: a historical perspective. Am J Primatol 73(8):720-730

Capitanio JP (1999) Personality dimensions in adult male rhesus macaques: prediction of behaviors across time and situation. Am J Primatol 47:299-320

Carne C, Viper S, Semple S (2011) Reciprocation and interchange of grooming, agonistic support, feeding tolerance, and aggression in semi-free-ranging Barbary macaques. Am J Primatol 73:1127-1133

Castles DL, Aureli F, de Waal FBM (1996) Variation in conciliatory tendency and relationship quality across groups of pigtail macaques. Anim Behav 52:389-403

Chakraborty D, Ramakrishnan U, Panor J, Mishra C, Sinha A (2007) Phylogenetic relationships and morphometric affinities of the Arunachal macaque Macaca munzala, a newly described primate from Arunachal Pradesh, Northeastern India. Mol Phylogenetics Evol 44:838-849

Chan LKW (1996) Phylogenetic interpretations of primate socioecology: with special reference to social and ecological diversity in Macaca. In: Martins EP (ed) Phylogenies and the comparative method in animal behaviour. Oxford University Press, Oxford, pp 324-360

Clutton-Brock TH, Harvey P (1977) Primate ecology and social organization. J Zool 183:1-39

Clutton-Brock TH, Janson CH (2012) Primate socioecology at the crossroads: past, present, and future. Evol Anthropol 21:136-150

Cobb S (1976) Social support as a moderator of life stress. Psychosom Med 38:300-314

Cohen S, Janicki-Deverts D, Miller GE (2007) Psychological stress and disease. JAMA 298:1685-1687

Cohen S, Janicki-Deverts D, Turner RB, Doyle WJ (2015) Does hugging provide stress-buffering social support? A study of susceptibility to upper respiratory infection and illness. Psychol Sci 26:135-147

Cooper MA (1999) Social tolerance in Assamese macaques (Macaca assamensis). Ph.D. Dissertation. University of Georgia, Athens, GA

Cooper MA, Bernstein IS (2002) Counter aggression and reconciliation in Assamese macaques (Macaca assamensis). Am J Primatol 56:215-230

Cooper MA, Bernstein IS (2008) Evaluating dominance styles in Assamese and rhesus macaques. Int J Primatol 29:225-243

Cords M (2013) The behavior, ecology, and social evolution of Cercopithecine monkeys. In: Mitani JC, Call J, Kappeler PM, Palombit RA, Silk JB (eds) The evolution of primate societies. University of Chicago Press, Chicago, pp 91-112

Csardi G, Nepusz T (2006) The igraph software package for complex network research. InterJ. Complex Syst. 1695

de Vries H (1998) Finding a dominance order most consistent with a linear hierarchy: a new procedure and review. Anim Behav 55:827-843 
de Vries H, Stevens JMG, Vervaecke H (2006) Measuring and testing the steepness of dominance hierarchies. Anim Behav 71:585-592

de Waal FBM, Luttrell LM (1989) Towards a comparative ecology of the genus Macaca: different dominance styles in rhesus and stumptailed macaques. Am J Primatol 19:83-109

de Waal FBM, Yoshihara D (1983) Reconciliation and redirected affection in rhesus monkeys. Behaviour 85:224-241

Demaria C, Thierry B (2001) A comparative study of reconciliation in rhesus and Tonkean macaques. Behaviour 138:397-410

Deng ZY (1993) Social development of infants of Macaca thibetana at Mt. Emei, China. Folia Primatol 60:28-35

Duboscq J, Micheletta J, Agil M, Hodges K, Thierry B, Engelhardt A (2013) Social tolerance in wild female crested macaques (Macaca nigra) in Tangkoko-Batuangus Nature Reserve, Sulawesi, Indonesia. Am J Primatol 75:361-375

Farine DR, Whitehead H (2015) Constructing, conducting and interpreting animal social network analysis. J Anim Ecol 84:1144-1163

Fooden J (1986) Taxonomy and evolution of the sinica group of macaques: 5. Overview of natural history. Fieldiana Zool 29:1-22

Fruteau C, van de Waal E, Van Damme E, Noe R (2011) Infant access and handling in sooty mangabeys and vervet monkeys. Anim Behav 81:153-161

Fujii K, Fushing H, Beisner BA, McCowan B (2013) Computing power structures in directed biosocial networks: flow percolation and imputed conductance. Technical Report, Department of Statistics, UC Davis

Gammell MP, de Vries H, Jennings DJ, Carlin CM, Hayden TJ (2003) David's score: a more appropriate dominance ranking method than Clutton-Brock et al.'s index. Anim Behav 66:601-605

Greenwood PJ (1980) Mating systems, philopatry and dispersal in birds and mammals. Anim Behav 28:1140-1162

Griffin RH, Nunn CL (2012) Community structure and the spread of infectious disease in primate social networks. Evol Ecol 26(4):779-800

Gumert MD (2007) Grooming and infant handling interchange in Macaca fascicularis: the relationship between infant supply and grooming payment. Int J Primatol 28:1059-1074

Hamilton WD (1964) The genetical evolution of social behaviour I/II. J Theor Biol 7:1-52

Handcock M, Hunter D, Butts C, Goodreau S, Morris M (2006) Statnet: an R package for the statistical analysis and simulation of social networks. University of Washington. http://www. csde.washington.edu/statnet

Hemelrijk C (1999) An individual-orientated model of the emergence of despotic and egalitarian societies. Proc R Soc Lond B 266:361-369

Hemelrijk C (2005) Self-organisation and evolution of biological and social systems. Cambridge University Press, Cambridge

Henzi SP, Barrett L (2002) Infants as a commodity in a baboon market. Anim Behav 63:915-921

Hill DA (1999) Effects of provisioning on the social behaviour of Japanese and rhesus macaques: implications for socioecology. Primates 40:187-198

Hinde RA (1976) Interactions, relationships and social structure. Man 11:1-17

Holt-Lunstad J, Smith TB, Layton JR (2010) Social relationships and mortality risk: a meta-analytic review. PLoS Med 7:e1000316

Horiuchi S (2007) Social relationships of male Japanese macaques (Macaca fuscata) in different habitats: a comparison between Yakushima island and Shimokita peninsula populations. Anthropol Sci 115:63-65

House JS, Landis KR, Umberson D (1988) Social relationships and health. Science 241:50-54

Isbell LA (2017) Socioecological model. In: Bezanson M, MacKinnon KC, Riley E, Campbell CJ, Nekaris KAI, Estrada A, Di Fiore AF, Ross S, Jones-Engel LE, Thierry B, Sussman RW, Sanz C, Loudon J, Elton S, Fuentes (eds) The international encyclopedia of primatology. Wiley Online Library 
Judge P (2000) Coping with crowded conditions. In: Aureli F, de Waal FBM (eds) Natural conflict resolution. University of California Press, Berkeley, pp 129-154

Kaburu SSK, Newton-Fisher NE (2015) Egalitarian despots: hierarchy steepness, reciprocity and the grooming-trade model in wild chimpanzees, Pan troglodytes. Anim Behav 99:61-71

Kalbitz J, Ostner J, Schulke O (2016) Strong, equitable and long-term social bonds in the dispersing sex in Assamese macaques. Anim Behav 113:13-22

Kamilar J, Cooper N (2015) Phylogenetic signal in primate behaviour, ecology and life history. Philos Trans R Soc B 368:20120341

Kaplan JR, Heise ER, Manuck SB, Shively CA, Cohen S, Rabin BS, Kasprowicz AL (1991) The relationship of agonistic and affiliative behavior patterns to cellular immune function among cynomolgus monkeys Macaca- fascicularis living in unstable social groups. Am J Primatol 25 (3):157-174

Kappeler PM (2000) Primate males: causes and consequences of variation in group composition. Cambridge University Press, Cambridge

Kappeler PM, Van Schaik CP (2002) Evolution of primate social systems. Int J Primatol 23:707-740

Kappeler PM, Cremer S, Nunn CL (2015) Sociality and health: impacts of sociality on disease susceptibility and transmission in animal and human societies. Philos Trans R Soc B 370:20140116

Kapsalis E (2004) Matrilineal kinship and primate behavior. In: Chapais B, Berman CM (eds) Kinship and behavior in primates. Oxford University Press, New York, pp 153-176

Kasper C, Voelkl B (2009) A social network analysis of primate groups. Primates 50:343-256

Koenig A, Scarry CJ, Wheeler BC, Borries C (2013) Variation in grouping patterns, mating systems and social structure: what socio-ecological models attempt to explain. Philos Trans R Soc B 368:20120348

Krause J, James R, Croft DP (2010) Personality in the context of social networks. Philos Trans R Soc B 365:4099-4106

Lemey P, Rambaut A, Drummond AJ, Suchard MA (2009) Bayesian phylogeography finds its roots. PLoS Comput Biol 5:e1000520

Li J (1999) The Tibetan macaque society: a field study. Anhui University Press, Hefei

Li J, Wang Q (1996) Dominance hierarchy and its chronic changes in adult male Tibetan macaques (Macaca thibetana). Acta Zool Sinica 42:330-334

Lusseau D (2003) The emergent properties of a dolphin social network. Proc R Soc Lond B 270: S186-S188

MacIntosh AJJ, Jacobs A, Garcia C, Shimizu K, Mouri K, Huffman MA, Hernandez AD (2012) Monkeys in the middle: parasite transmission through a social network of a wild primate. PLoS One 7:e51144

Majolo B, Ventura R, Koyama NF, Hardie SM, Jones BM, Knapp LA, Schino G (2009) Analyzing the effects of group size and food competition on Japanese macaque social relationships. Behaviour 146:113-137

Marechal L, Semple S, Majolo B, Qarro M, Heistermann M, MacLarnon A (2011) Impacts of tourism on anxiety and physiological stress levels in wild male Barbary macaques. Biol Conserv 144(9):2188-2193

Matsumura S (1999) The evolution of "egalitarian" and "despotic" social systems among macaques. Primates 40:23-31

Newman MEJ, Girvan M (2004) Finding and evaluating community structure in networks. Phys Rev E 69:1-15

Nunn CL (2011) The comparative approach in evolutionary anthropology and biology. University of Chicago Press, Chicago

Nunn CL (2012) Primate disease ecology in comparative and theoretical perspective. Am J Primatol 74(6):497-509

Nunn CL, Thrall PH, Leendertz FH, Boesch C (2011) The spread of fecally transmitted parasites in socially structured populations. PLoS One 6:e21677 
Nunn CL, Jordan F, McCabe CM, Verdolin JL, Fewell JH (2015) Infectious disease and group size: more than just a numbers game. Philos Trans R Soc B 370:20140111

Ogawa H (1995) Bridging behavior and other affiliative interactions among male Tibetan macaques (Macaca thibetana). Int J Primatol 16:707-729

Ostner J, Schülke O (2014) The evolution of social bonds in primate males. Behaviour 151:871-906

Pagel M, Meade A, Barker D (2004) Bayesian estimation of ancestral character states on phylogenies. Syst Biol 53(5):673-684

Paul A, Kuester J (1987) Dominance, kinship and reproductive value in female Barbary macaques (Macaca sylvanus) at Affenberg Salem. Behav Ecol Sociobiol 21:323-331

Petit O, Abegg C, Thierry B (1997) A comparative study of aggression and conciliation in three cercopithecine monkeys (Macaca fuscata, Macaca nigra and Papio papio). Behaviour 134:415-432

Preuschoft S, Paul A (2000) Dominance, egalitarianism, and stalemate: an experimental approach to male-male competition in Barbary macaques. In: Kappeler PM (ed) Primate males: causes and consequences of variation in group composition. Cambridge University Press, Cambridge, pp 205-216

Preuschoft S, Paul A, Kuester J (1998) Dominance styles of female and male Barbary macaques (Macaca sylvanus). Behaviour 135:731-755

Puga I, Sueur C (2017) Emergence of complex social networks from spatial structure and rules of thumb: a modelling approach. Ecol Complex 31:189-200

Purvis A (1995) A composite estimate of primate phylogeny. Philos Trans R Soc B 348:405-421

Ram S, Venkatachalam S, Sinha A (2003) Changing social strategies of wild female bonnet macaques during natural foraging and on provisioning. Curr Sci 84:780-790

Ree RH, Smith SA (2008) Maximum likelihood inference of geographic range evolution by dispersal, local extinction, and cladogenesis. Syst Biol 51:4-14

Revell LJ (2012) phytools: an R package for phylogenetic comparative biology (and other things). Methods Ecol Evol 3:217-233

Richter C, Mevis L, Malaivijitnond S, Schülke O, Ostner J (2009) Social relationships in freeranging male Macaca arctoides. Int J Primatol 30(4):625-642

Romano V, Duboscq J, Sarabian C, Thomas E, Sueur C, MacIntosh AJJ (2016) Modeling infection transmission in primate networks to predict centrality-based risk. Am J Primatol 78:767-779

Sade DS (1972) A longitudinal study of social behavior of rhesus monkeys. In: Tuttle R (ed) The functional and evolutionary biology of primates. Aldine-Atherton, Chicago, pp 378-398

Sapolsky RM (2005) The influence of social hierarchy on primate health. Science 308:648-652

Schino G, Aureli F (2008) Tradeoffs in primate grooming reciprocation: testing behavioral flexibility and correlated evolution. Biol J Linn Soc 95:439-446

Schülke O, Ostner J (2008) Male reproductive skew, paternal relatedness, and female social relationships. Am J Primatol 70:695-698

Schülke O, Ostner J (2013) Ecological and social influences on sociality. In: Mitani JC, Call J, Kappeler PM, Palombit RA, Silk JB (eds) Evolution of primate societies. University of Chicago Press, Chicago, pp 195-219

Schülke O, Bhagavatula J, Vigilant L, Ostner J (2010) Social bonds enhance reproductive success in male macaques. Curr Biol 20:2207-2210

Schülke O, Wenzel S, Ostner J (2013) Paternal relatedness predicts the strength of social bonds among female rhesus macaques. PLoS One 8:e59789

Shizuka D, Mcdonald DB (2012) A social network perspective on measurements of dominance hierarchies. Anim Behav 83:925-934

Sih A, Bell A, Chadwick Johnson J (2004) Behavioral syndromes: an ecological and evolutionary overview. Trends Ecol Evol 19:372-378

Sih A, Cote J, Evans M, Fogarty S, Pruitt J (2012) Ecological implications of behavioural syndromes. Ecol Lett 15:278-289 
Silk JB (1994) Social relationships of male bonnet macaques: male bonding in a matrilineal society. Behaviour 130:271-291

Silk JB (1999) Male bonnet macaques use information about third-party rank relationships to recruit allies. Anim Behav 58:45-51

Silk JB, Alberts SC, Altmann J (2003) Social bonds of female baboons enhance infant survival. Science 302:1231-1234

Silk JB, Beehner JC, Bergman C, Crockford AL, Engh LR, Moscovice RM, Wittig RM, Seyfarth RM, Cheney DL (2010) Strong and consistent social bonds enhance the longevity of female baboons. Curr Biol 20:1359-1361

Sinha A, Mukhopadhyay K, Datta-Roy A, Ram S (2005) Ecology proposes, behaviour disposes: ecological variability in social organization and male behavioural strategies among wild bonnet macaques. Curr Sci 89(7):1166-1179

Sterck EHM, Watts DP, van Schaik CP (1997) The evolution of female social relationships in nonhuman primates. Behav Ecol Sociobiol 41(5):291-309

Sueur C, Petit O, De Marco A, Jacobs AT, Watanabe K, Thierry B (2011) A comparative network analysis of social style in macaques. Anim Behav 82(4):845-852

Suomi SJ (2011) Risk, resilience, and gene-environment interplay in primates. J Can Acad Child Adolesc Psychiatry 20:289-297

Thierry B (1985) Patterns of agonistic interactions in three species of macaque (Macaca mulatta, M. fascicularis, M. tonkeana). Aggress Behav 11:223-233

Thierry B (2000) Covariation of conflict management patterns across macaque species. In: Aureli F, de Waal FBM (eds) Natural conflict resolution. University of California Press, Berkley, CA, pp $106-128$

Thierry B (2004) Social epigenesis. In: Thierry B, Singh M, Kaumanns W (eds) Macaque societies: a model for the study of social organization. Cambridge University Press, Cambridge, pp 267-290

Thierry B (2007) Unity in diversity: lessons from macaque societies. Evol Anthropol 16:224-238

Thierry B (2013) The macaques: a double-layered social organization. In: Campbell CJ, Fuentes A, MacKinnon KC, Bearder SK, Stumpf RM (eds) Primates in perspective. Oxford University Press, Oxford, pp 229-240

Thierry B, Aureli F (2006) Barbary but not barbarian: social relations in a tolerant macaque. In: Hodges JK (ed) Biology and behaviour of Barbary macaques. Nottingham University Press, Nottingham, pp 1-18

Thierry B, Iwaniuk AN, Pellis SM (2000) The influence of phylogeny on the social behaviour of macaques. Ethology 106:713-728

Thierry B, Singh M, Kaumanns W (2004) Macaque societies: a model for the study of social organization. Cambridge University Press, Cambridge

Thierry B, Aureli F, Nunn CL, Petit O, Abegg C, de Waal FBM (2008) A Comparative study of conflict resolution in macaques: insights into the nature of covariation. Anim Behav 75:847-860

Tiddi B, Aureli F, Schino G (2010) Grooming for infant handling in tufted capuchin monkeys: a reappraisal of the primate infant market. Anim Behav 79:1115-1123

Tosi AJ, Morales JC, Melnick DJ (2003) Paternal, maternal, and biparental molecular markers provide unique windows onto the evolutionary history of macaque monkeys. Evolution 57:1419-1435

Tyrrell M, Berman CM, Agil M, Sutrisno T, Engelhardt A (2018) Social style among wild male crested macaques (Macaca nigra) in Tangkoko Nature Reserve, Sulawesi, Indonesia. In Proceedings of the American Society of Primatologists, San Antonio, TX

van Hooff JARAM, van Schaik C (1994) Male bonds: affiliative relationships among nonhuman primates. Behaviour 130:309-337

van Schaik CP (1989) The ecology of social relationships amongst female primates. In: Standen V, Foley RA (eds) Comparative socio-ecology: the behavioral ecology of humans and other animals. Blackwell, Oxford, pp 195-218 
van Schaik CP (1996) Social evolution in primates: the role of ecological factors and male behaviour. Proc Br Acad 88:9-31

van Schaik CP, Pandit AP, Vogel ER (2004) A model for within-group coalitionary aggression among males. Behav Ecol Sociobiol 57:101-109

Veenema HC, Das M, Aureli F (1994) Methodological improvements for the study of reconciliation. Behav Process 31:29-38

Ventura R, Majolo B, Koyama NF, Hardie SM, Schino G (2006) Reciprocation and interchange in wild Japanese macaques: grooming, cofeeding and agonistic support. Am J Primatol 68:1138-1149

Wada KC, Xiong C, Wang Q (1987) On the distribution of Tibetan and rhesus monkeys in Southern Anhui, China. Acta Theriol Sinica 7:148-176

Widdig A (2013) The impact of male reproductive skew on kin structure and sociality in multi-male groups. Evol Anthropol 22:239-250

Wrangham RW (1980) An ecological model of female-bonded primate groups. Behaviour 75:262-300

Xiong CP (1984) Ecological studies of the stump-tailed macaque. Acta Theriol Sinica 4:1-9

Young C, Majolo B, Heistermann M, Schulke O, Ostner J (2014) Responses to social and environmental stress are attenuated by strong male bonds in wild macaques. PNAS 111:18195-18200

Zhang P, Watanabe K (2014) Intraspecies variation in dominance style of Macaca fuscata. Primates 55:69-79

Zhao QK (1996) Etho-ecology of Tibetan macaques at Mount Emei, China. In: Fa JE, Lindburg DG (eds) Evolution and ecology of macaque societies. Cambridge University Press, Cambridge, pp 263-289

Zhao QK, Deng ZY, Xu J (1991) Natural foods and their ecological implications for Macaca thibetana at Mount Emei, China. Folia Primatol 57:1-15

Open Access This chapter is licensed under the terms of the Creative Commons Attribution 4.0 International License (http://creativecommons.org/licenses/by/4.0/), which permits use, sharing, adaptation, distribution and reproduction in any medium or format, as long as you give appropriate credit to the original author(s) and the source, provide a link to the Creative Commons licence and indicate if changes were made.

The images or other third party material in this chapter are included in the chapter's Creative Commons licence, unless indicated otherwise in a credit line to the material. If material is not included in the chapter's Creative Commons licence and your intended use is not permitted by statutory regulation or exceeds the permitted use, you will need to obtain permission directly from the copyright holder. 